

\section{The Philosophy and Science of Predictive Processing}


Also available from Bloomsbury

Advances in Experimental Philosophy of Mind, edited by Justin Sytsma

Advances in Experimental Philosophy of Science, edited by Daniel A. Wilkenfeld, Richard Samuels Arguing from Cognitive Science of Religion, by Hans Van Eyghen Great Philosophical Objections to Artificial Intelligence, by Eric Dietrich, John P. Sullins, Bram van Heuveln, Chris Fields, Robin Zebrowski

Methodological Advances in Experimental Philosophy, edited by Eugen Fischer, Mark Curtis Philosophy in a Technological World, by James Tartaglia 


\section{The Philosophy and Science of Predictive Processing}

Edited by Dina Mendonça, Manuel Curado, and

Steven S. Gouveia 


\section{BLOOMSBURY ACADEMIC}

Bloomsbury Publishing PlC

50 Bedford Square, London, WC1B 3DP, UK

1385 Broadway, New York, NY 10018, USA

BLOOMSBURY, BLOOMSBURY ACADEMIC and the Diana logo are trademarks of Bloomsbury Publishing Plc

First published in Great Britain 2021

Copyright $\odot$ Dina Mendonça, Manuel Curado, Steven S. Gouveia and Contributors, 2021

Dina Mendonça, Manuel Curado and Steven S. Gouveia has asserted their right under the Copyright, Designs and Patents Act, 1988, to be identified as Editors of this work.

For legal purposes the Acknowledgments on $\mathrm{p}$. xviii constitute an extension of this copyright page.

Cover design by Charlotte Daniels Cover image @ 4X-image / iStock

All rights reserved. No part of this publication may be reproduced or transmitted in any form or by any means, electronic or mechanical, including photocopying, recording, or any information storage or retrieval system, without prior permission in writing from the publishers.

Bloomsbury Publishing Plc does not have any control over, or responsibility for, any third-party websites referred to or in this book. All internet addresses given in this book were correct at the time of going to press. The author and publisher regret any inconvenience caused if addresses have changed or sites have ceased to exist, but can accept no responsibility for any such changes.

A catalogue record for this book is available from the British Library.

Library of Congress Cataloging-in-Publication Data

Names: Mendonça, Dina, editor. | Curado, Manuel, 1967- editor. | Gouveia, Steven S., editor.

Title: The philosophy and science of predictive processing / edited by

Dina Mendonça, Manuel Curado and Steven S. Gouveia.

Description: New York, NY : Bloomsbury Academic, 2020. | Includes bibliographical references and index.

Identifiers: LCCN 2020033552 (print) | LCCN 2020033553 (ebook) |

ISBN 9781350099753 (hardback) | ISBN 9781350197299 (paperback) |

ISBN 9781350099760 (ePDF) | ISBN 9781350099777 (eBook)

Subjects: LCSH: Psychology-Methodology. | Prediction (Psychology) | Cognitive science. | Neurosciences.

Classification: LCC BF38.5 .P478 2020 (print) | LCC BF38.5 (ebook) | DDC 150.1/12-dc23

LC record available at https://lccn.loc.gov/2020033552

LC ebook record available at https://lccn.loc.gov/2020033553

ISBN: $\quad H B: \quad 978-1-3500-9975-3$

ePDF: 978-1-3500-9976-0

eBook: 978-1-3500-9977-7

Typeset by Integra Software Services Pvt. Ltd.,

To find out more about our authors and books visit www.bloomsbury.com and sign up for our newsletters. 


\title{
The Phenomenology and Predictive Processing of Time in Depression
}

\author{
Zachariah A. Neemeh \\ Department of Philosophy, University of Memphis, United States \& Institute for \\ Intelligent Systems, University of Memphis, United States \\ Shaun Gallagher \\ Department of Philosophy, University of Memphis, United States \& Faculty of Law, \\ Humanities and the Arts, University of Wollongong, Australia
}

\section{Introduction}

Predictive processing has been characterized as an "intermediate-level model" that at once abstracts from neural architecture while remaining below the level of conscious awareness (Spratling 2013). It is the "Bayesian brain" that performs predictive processing-or, in less neurocentric formulations, it is the Bayesian brain together with its body that engages with its world according to predictive processing principles (Clark 2013, 2016, Gallagher and Allen 2018). Whatever brains and bodies are doing in this regard, there is a correlatively rich phenomenology, understood not just as a phenomenal "what it is like," but as phenomenologists in the tradition of Edmund Husserl describe, as a dynamically structured flow of intentional experience. Phenomenology describes not the phenomenal surface, but rather the stable and relatively invariant structures that allow for the orderliness of experience. Rather than being a swirling, fluxional chaos of sense data, the stream of consciousness is ordered by regularities.

In this chapter, we focus on time, or, more precisely, on the intrinsic temporality of consciousness. Although the ticking of the clock or the decay of radioactive isotopes occurs in a regular and invariable sequence, the experience of time is variable. It can appear to slow down, as in periods of boredom. It can seem to speed up, as when we are engrossed in an activity or caught up in playing a game. In the early twentieth century, Harry L. Hollingworth (1910) noted that stimuli of longer and shorter durations tend to be judged as equal around the central mean of their distributionsthe "central tendency effect" (see Shi and Burr 2016). That is, phenomena shorter in duration than is typical of phenomena of that type tend to be judged as longer than they are; phenomena longer in duration than is typical tend to be judged as shorter 
than they really are. Even earlier, at the beginning of psychophysical research into time perception, Karl von Vierordt (1863) noted a similar effect. Known as "Vierordt's law," subjects tend to perceive shorter intervals as longer and longer intervals as shorter. These effects are only some of many factors that alter the perception of time. Different sensory modalities, processing in different neural circuits, process at faster or slower temporal velocities. Audition reaches early sensory areas quicker than vision. Activation of primary visual cortex (V1) is usually assumed to occur 45-55 milliseconds after stimulus; auditory input reaches the cortex in less than half the time (9 to 15 milliseconds) (Clark et al. 1995, Foxe and Simpson 2002, Vaughan and Arezzo 1988, Vaughan et al. 1980). These are not differences that we experience; experientially, however, auditory phenomena are often perceived as longer in duration from equally long visual phenomena (Shi and Burr 2016, Wearden et al. 2006). Time perception varies by age, for example, and the perception of calendric time tends to speed up in older persons (Friedman 1990). Time perception can also vary across cultures and may be markedly different in those not dominated by the regime of the clock (Telban 2017; for an early iteration of this idea, see Whorf $1956^{1}$ ).

Husserl (1991), influenced by his reading of James, analyzed the intrinsic subjective temporal flow of experience in terms of formal, transcendental structures of consciousness related to intentionality: retention, primal impression, protention. $\mathrm{He}$ sought to capture not only the perception of time but also the genesis of the specious present-the aspect of the experience of present time as nonpunctual that includes a past and future temporal extension (James 1890) - and experience itself as temporal. Recent analyses in predictive processing complement the phenomenological approach to time. In the hierarchical arrangement of predictive processing, different regularities are processed across multiple timescales (fast and more detailed vs. slow and more abstract) (Hohwy 2013: 27). Changes in such processes can modulate the relations of retention-primal impression-protention and generate different experiences of time. These phenomenological and empirical approaches to the structure of intrinsic temporality can help us understand experiences such as time dilation (the experiential deceleration of time), time contraction (the experiential acceleration of time), and other disturbances of the flow of time-especially as they manifest in depression.

In this chapter we first elucidate the subjective flow of time particularly as developed by Husserl. We next discuss time and timescales in predictive processing. We then consider how the phenomenological analysis of time can be naturalized within a predictive processing framework. In the final section, we develop an analysis of the temporal disturbances characteristic of depression using the resources of both phenomenology and predictive processing.

\section{The Phenomenology of Intrinsic Temporality}

Time holds a very privileged place in phenomenological thought. For the phenomenologist, rather than being a mere succession of instants, all experiences are permeated and structured by temporality. Spatial perception, for example, is typically explained in relatively static terms in the empirical literature. Merleau-Ponty, by 
contrast, discusses spatiality and depth perception as temporal phenomena, without denying the empirical lawlike relatedness of size to distance (Favela and Chemero 2016). Even phenomena that seem purely spatial in nature have a fundamentally temporal structure, as does human existence more generally (see Heidegger 2010). Merleau-Ponty summarizes this phenomenological view: "Time must be understood as a subject, and the subject must be understood as time" (1968: 445). Merleau-Ponty develops an understanding of temporality as an auto-affection that unfolds or generates both subjectivity and the world. Both Heidegger and Merleau-Ponty attempt to think of time as something nonrepresentational-not as a spatialized dimension, as in physics, but an originary unfolding of subjectivity and being (Heidegger 1972, 2012). In this regard, they follow the lead of Husserl, who defined subjective and intentional relations in terms of an originary temporalization. In this section, we review Husserl's original exposition of the temporality of subjectivity and intentionality and his notions of active and passive syntheses. In the following sections, we relate these syntheses to the integration of multiple timescales in predictive processing.

Objective time is sometimes conceived of as a container, line, or series of momentary points. Husserl (1991) is keen to differentiate his phenomenological investigation of temporality from objective, numerical, or spatialized conceptions of time. He does not seek to ascertain how many seconds or milliseconds the perceived present or the "now" encompasses-which is generally recognized among psychologists as nonpunctual and in some theories extending up to 30 seconds (Baddeley 2007, James 1890, Wearden 2016). It is not that chronometric time is irrelevant-“it does interest us that data 'in objective time' are meant in these experiences" (Husserl 1991: 10). By bracketing objective time, however, he thinks we are able to reveal a more originary intrinsic temporal structure in subjectivity-a "time-constituting consciousness" (ibid., 28) - which helps to explain how it is even possible to experience meant objects that extend in objective time.

Naiive reflection or introspection may operate on a preconception that the subject is living in a punctiform present, with this point moving along a metaphorical line with a past receding backwards and a future yet to come (see Figure 11.1). Time is centered upon the present or the now, and the past and future are, respectively, presents that are no longer and presents that are yet to come. The past nows are representations of the presents they once were, and these representations can be more or less vivid or dull.

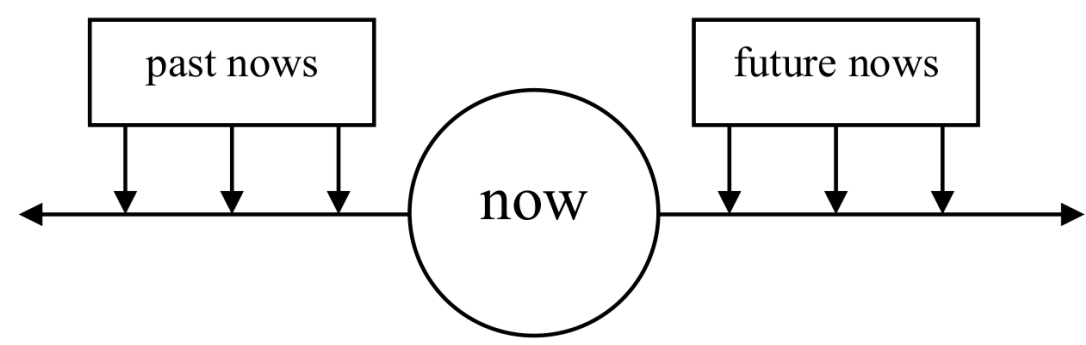

Figure 11.1 The naïve or pre-phenomenological conception of subjective time. 
The naïve subject who reports her experience of time to the psychophysicist already conceives of her experience of time in terms of an objective linearity. The chronometric time of psychophysical experimentation is itself a refinement of the folk concept (Heidegger 2012, Husserl 1991). Phenomenology calls for a different way of thinking of temporality rather than a refinement of the folk concept. The phenomenology of time is not merely a careful reflection on the sequence, duration, or timing of our experiences framed in terms of this folk concept; it is not simply a careful description and analysis of the subjective flow of time. Rather, Husserl reconceives of temporality as a structuring or genesis of the movement of the modes of intentionality. As Merleau-Ponty says, "Time is not a line, but rather a network of intentionalities" (2012: 440). It's a processual network structured by three temporal aspects: retention, primal impression, and protention. In regard to this structure, Husserl distinguishes between processes of active and passive syntheses. Both types of synthesis have the same basic retentional-impressional-protentional form. Active synthesis is manifest in the embodied activities of the subject. Passive synthesis occurs in the background processes outside of and surrounding the active focus of the subject. Husserl calls this structure a "passive synthesis" because it is not actively undertaken by the subject or by a homuncular controller. ${ }^{2}$

Husserl initially conceived of the primal impression as an originary awareness of the occurrent moment of the perceived object, which then slips into retention as that moment passes. In the later Bernau Manuscripts, the primal impression is reconceived as the intersection of retention and protention (Gallagher 2017a, Gallagher and Zahavi 2014). That is, retention and protention together interlace and constitute the immediate "living present" experience, which means that the primal impression is never given raw without protentional and retentional mediation. Husserl continually returns to the example of listening to musical notes. When a note is heard, the immediately palpable and visceral sounding occurs and registers in primal impression. However, a mere series of such nows cannot be all there is since there would be no connection between them; a note would appear and disappear followed by another note that would do the same; this would be a succession of experiences that would not be an experience of succession. Rather, as the note runs off it is modified by the retentional process, and it is maintained in the living present, but with the intentional sense as just past. "The tone itself is the same, but the tone 'in the manner in which' it appears is continually different" (Husserl 1991: 27). If the note is sounded for 1 second, the note qua intentional object perdures throughout the duration of this second and then stops. The intentional sense of this note continues to perdure in retention even after the physical vibrations and psychophysical sensations have died down. As Merleau-Ponty writes, "For every moment that arrives, the previous moment suffers a modification: I still hold it in hand, it is still there, and yet it already sinks back, it descends beneath the line of presents" (2012: 439).

The retention of just past notes allows me to hear the melody as such. Retention in this sense is part of the structure of the perception of the melody; it's not an act of memory that is added to perception to provide a representation of something in the past, but rather the continuation in the present of the trajectory of the intentional object-in this case, the note. "It is [perceptual] consciousness of what has just 
been" (Husserl 1991: 34). Protention is a pre-reflective anticipation of the imminent transformations to occur in the perceived object. When I hear a note within a melody, I have some anticipations of what is about to come next-anticipations that may be more or less vague. I may not know exactly what will come, but I will be surprised if a completely unexpected sound appears next. Even in the middle of a piece by Philip Glass, I may not know exactly what will come next, but I do have a sense that it will be a typical Philip Glass move, and I would be surprised to hear some conventionally ordered composition.

For Husserl and Merleau-Ponty, the possibility of hearing a melody as an extended object, not simply one note in an isolated instant followed by a further note, is evidence that the experienced or lived present is constituted by a temporal structure that includes the impression integrated with retentional and protentional moments. This interweaving of just-past, now-present, and just-about-to-be in the intentionality structure of awareness is effected in an ongoing process of passive synthesis, and this constitutes the intrinsic temporality of consciousness. When I listen to you utter a sentence, the only objectively present phenomenon is the occurrent word (or part thereof) that you are currently speaking. However, for me to hear you utter that word as part of a sentence, I have to hold or retain the previous part of the sentence as you continue to finish it. In addition, as I listen to you speak, I anticipate where your sentence is heading. If, for example, you start to utter the sentence "Mary had a little lamb ..., " at the point where you say "little," I hear that word (in the now extant primal impression [pi]) within the context of a fuller grouping constituted by a train of retention ( $\mathrm{r}$ ) and a projection of protention ( $\mathrm{p}$ ).

The threefold structuring process of intrinsic temporality is relational, and it is only through the interrelation of its component processes that pre-reflective consciousness is generated (Fuchs 2013b). None of its three moments is separable from the other. Retention and protention work together to shape the primal impression, and vice versa, forming a synthesis. This process of passive synthesis (that Husserl sometimes calls "auto-affection") importantly has a conative aspect. Fuchs (2013b: 78) calls this "the

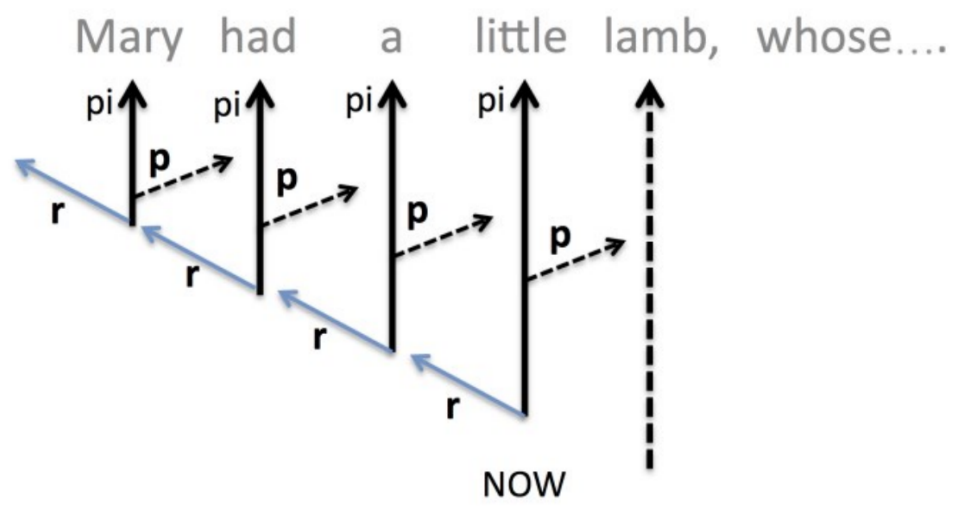

Figure 11.2 Intrinsic temporal structure. 
basic 'energetic' momentum of mental life which can be expressed with such concepts as drive, striving, and urge or affection" (see Husserl 2001: 280, Minkowski 1970). That is, the temporal movement of cognition is driven in part by affective salience. Passive synthesis structures most elements of experience and forms a background condition on which some object or set of objects may be thematized based on what may be the most affectively salient features for the subject. Husserl (2001: 280) writes: "Already within passivity, affection is a specific modality of objectivation for the ego. The ego is aroused in a special way here, although it does not yet orient itself actively."

Affectivity can draw the interest of the active subject. When an event or object has a high-enough affective salience, it becomes thematized as the explicit focus of active consciousness or attentional focus. Husserl calls this the movement from passive to active synthesis. Passive syntheses, however, constantly have an affective component; it is only when that affectivity becomes salient enough that a specific region is attentionally focused upon. This drives a bodily "I can" or mode of will based in the basic affective moment of the syntheses of time:

The will is not a separate mode of consciousness, but rather a special and higher form of activity that can appear everywhere under certain essential conditions that lie in presupposed objectivations and intentionality of feelings.

(ibid., 282-83)

The retention-primal impression-protention structure of intrinsic temporality characterizes not only the intentionality of consciousness but also the dynamical organization of intentional movement and action (Gallagher 2011); insofar as it is implicated in the "I can," intrinsic temporality is enactive or action-oriented (Gallagher and Zahavi 2014). Like affect, practical interests and doings also have an effect on our temporal experience. Intrinsic temporality, together with the affective and embodied action-oriented aspects of existence, together "form the intentional arc of attention, perception and action" (Fuchs 2013b: 79).

This is an important part of the analysis of intrinsic temporality that allows us to address the subjective variations in experience. The phenomenon of intentional binding shows that an agent's experience of time between initiation of action and action effect is modulated by intention (Moore and Obhi 2012). The appraisal of the relevance of a goal, or of a potential reward, has been shown to lengthen the perceived duration of an event (Fung et al. 2017, Uusberg et al. 2018). The perception of danger likewise can slow down the perception of time (Friedman 1990: 20). Negative emotions like anger can have the opposite effect, shortening the perceived duration of an event (Gable et al. 2016). Intense exercise and mindfulness meditation can both provoke a sense of time speeding up (Edwards and McCormick 2017, Thönes and Wittmann 2016). Certain psychopathologies can also alter the perception of time and the duration of events. While time perception is typically highly context-sensitive (Van Hedger et al. 2017), some psychopathologies are associated with chronic alterations in time perception. In PTSD, the past continues to erupt into the present. In depression, phenomenological psychiatrists have charted the different ways in which time perception becomes static and hollowed out, no longer feeling like a dynamic movement (Fuchs 2001, 2013a, 2013b, Jaspers 1997, Minkowski 1970, Ratcliffe 2012, 2015, Straus 1947). 


\section{Time in Predictive Processing}

As with phenomenology, time holds a privileged position within predictive processing. Predictive processing models cognition as a Bayesian process of prediction error minimization (PEM) (Friston 2005, Friston and Kiebel 2009). Whereas classical computational frameworks for understanding perception, such as that of David Marr (2010), model perception as a largely bottom-up process, predictive processing emphasizes top-down and lateral mechanisms of inference. ${ }^{3}$ Instead of passively representing the world based on afferent signals, the cognitive system actively creates a series of predictions about the state of the world and its contents. On a more minute scale, neuronal activity in the hierarchically arranged perceptual system predict the cause of the incoming sensory signals. These predictions attempt to chart the most probable external state of the world based on prior learning and experience (Doya et al. 2007). While predictions at a cortically lower level may seek to interpret the immediate perceptual datum at hand, higher-level predictions operate at longer timescales and anticipate subsequent states of the object or the world. In the PEM process predictions are continually updated against incoming information. It's likely that the incoming information will not exactly match the prior prediction. This mismatch between prior prediction (also called beliefs, priors, or hypotheses) and the actual state of affairs as perceived generates a prediction error. The surprise generated by the prediction error leads to the formation of a new prediction recalibrated for greater accuracy resulting in an updated posterior probability. The next time around, or at most after some number of learning trials, the prior will be more accurate than it was before. Still, the world will inevitably trump expectations, and the cycle of error production and prior recalibration will continue.

The notion of inference is an ambiguous one in predictive processing models. In PEM the concept of inference is not a personal-level operation undertaken by the agent; it's a subpersonal process that perhaps is only metaphorically inferential (see Hatfield 2002). Helmholtz (1962: 430) originally suggested that the processes of perception "are like inferences" (emphasis added). ${ }^{4}$ Hohwy indicates something similar. The causal inference conducted by the brain is "analogous in many respects to our everyday reasoning about cause and effect, and to scientific methods of causal inference" (emphasis added). He continues:

There is a sense in which, in spite of being Bayesian, [PEM] is more mechanical than it is inferential ... The 'neuronal hardware' of the mechanism itself is not literally inferential: neuronal populations are just trying to generate activity that anticipates their input.

(Hohwy 2013: 13, 55)

In this respect, one might think of the processes described in perceptual PEM as a kind of passive synthesis rather than an inference. Passive synthesis is informed by an association from past experience (what predictive models call a prior), which shapes "actual and possible expectations" (Husserl 2001: 119). Passive synthesis thus involves a process involving a horizon of expectations about the world, each with varying degrees of probability. 
In order for these predictions to operate, there must be relatively stable regularities in the world. These regularities operate at different timescales. The Bayesian system (on some accounts, the brain or the brain-body with its environment) hierarchically processes these regularities according to their respective timescales. Long-term regularities are the highest level and most abstract in the hierarchy. On the opposite end of the hierarchical scale are short-term regularities. The rapid, online predictions at short, elementary timescales of milliseconds facilitate the immediate perception of objects in the world. Within the brain, neuronal assemblies gear up to predict their imminent states. These short-term regularities and predictions are hierarchically ordered by coarser-grained predictions operating on slower/longer timescales. Predictions cascade downwards from slower timescales to faster timescales in a topdown fashion. This is "a dynamic, self-organizing system in which the inner (and outer) flow of information is constantly reconfigured" (Clark 2016: 3).

During action, predictions project the desired subsequent state onto the world. In this process, called active inference, the system physically modifies its environment in order to get a match between priors and posteriors. Perception, it must be noted, is equally as active as action itself. Whereas classical cognitive models view the mind as a passive machine developing representations of its input, predictive processing posits an active mind that generates its world (Clark 2016, Hutto 2018).

PEM, on a standard interpretation, moves through inferences to update hypotheses, hierarchically structured on varying timescales. Hohwy et al. (2016) use this PEM framework to explain the specious present. They then apply it to Husserl's phenomenological and Grush's (2008) computational accounts of the specious present. They present the phenomenological account as a temporal formalism of retention-primal impression-protention. They use this formal division to temporally distinguish the elements in Grush's $(2007,2008)$ theory, ${ }^{5}$ which they reformulate in terms of predictive processing. Retention is a smoothing or posterior updating. Primal impression is a filtering or prior updating. ${ }^{6}$ Protention is then the prediction such that "at $t$, the state estimate simultaneously has retention, via smoothing, primary impression, via filtering, and protention, via prediction" (Hohwy et al. 2016: 328).

They explain the movement of the temporal window, the flow or the perception of the passage of time by proposing that predictions' likelihood weightings rapidly drop, even while they continue to hold true. They refer to this instability metaphorically as a "distrust of the present."

The sense of flow arises as the system gives up one hypothesis and settles on a new one due to its propensity for distrusting the present. The current prior decreases [in likelihood] and this makes it seem like we are inexorably being pushed forward. The window of the specious present moves forward because the system expects change and therefore down-regulates the current input.

(ibid., 330)

The movement of the specious present is driven by a kind of meta-prediction that current hypotheses will rapidly be disproven as a result of imminent change. Protention is never perfectly fulfilled (there is always some degree of prediction error) 
and this drives the system to continue its processing. This explains phenomena such as the bistability of the Necker cube, where perception fails to settle on one single interpretation and instead shifts between two alternate predictions. The changes in the perception of the Necker cube are driven by the meta-prediction that current hypotheses will rapidly be replaced by new ones, although the input remains constant.

Hohwy, Paton, and Palmer's discussion of the specious present remains relatively abstract and disembodied, however. This is consistent with their internalism, as clearly expressed by Hohwy:

PEM should make us resist conceptions of [a mind-world] relation on which the mind is in some fundamental way open or porous to the world, or on which it is in some strong sense embodied, extended or enactive. Instead, PEM reveals the mind to be inferentially secluded from the world, it seems to be more neurocentrically skull-bound than embodied or extended, and action itself is more an inferential process on sensory input than an enactive coupling with the environment.

(Hohwy 2016: 259)

As we've noted, however, temporal experience can have significant affective and embodied components that modify the formal inferential structure of the specious present. These many affective and embodied temporal effects are significant for the phenomenology of intrinsic temporality. The specious present is not a phenomenon with constant dimensions but is subject to alteration under affective conditions. Husserl (2001: 280) and other phenomenologists allow for this and insist that, in addition to the formal temporal structure of retention-primal impression-protention, temporal consciousness is fundamentally driven forward by affectivity. Furthermore, this temporal structure is often realized within an embodied "I can" and its sensorimotor intentionalities. These more embodied and affective aspects can be integrated into a predictive processing account of the specious present by taking into account active inference, which includes exteroceptive, interoceptive, and proprioceptive aspects.

\section{Predictive Engagement and Affectivity in Intrinsic Temporality}

We propose a revised predictive processing account of intrinsic temporality enhanced by integrating affective and embodied elements of Husserl's phenomenological analyses and by emphasizing the dynamical integration of timescales. Time in predictive processing is ordered according to a hierarchical series of timescales, from the rapid/ shorter timescales of neural assemblies to the slower/longer timescales of goal-oriented behavior. The relations among different timescales are significant for understanding the phenomenology of intrinsic temporality. Francisco Varela (1999) provides a theoretical connection by introducing three timescales relevant to Husserlian intrinsic time: the elementary scale of neuronal processes (the 1/10 scale measured in milliseconds), the integrative scale of pre-reflective consciousness-the specious or living present (the 1 scale measured in seconds), and the narrative scale of projects and discourse (the 10 scale of longer time measures) (see Gallagher 2016, 2017a, 2017b, 2018). 
The elementary scale includes processes such as "the intrinsic cellular rhythms of neuronal discharges, and ... the temporal summation capacities of synaptic integration. These events fall within a range of 10 milliseconds (e.g., the rhythms of bursting interneurons) to $100 \mathrm{msec}$ (e.g., the duration of an EPSP/IPSP sequence in a cortical pyramidal neuron)" (Varela 1999: 117). The integrative timescale is the time of the flow of pre-reflective consciousness in the living present-the scale of a simple conscious act, a basic bodily action, or attention shift, ${ }^{7}$ operating from .5 to 3 seconds. It is called "integrative" because the cell assemblies firing at the elementary scale are synchronized and integrated at this level into larger-scale assemblies in ways that are coupled with (aligned with, attuned to) bodily and environmental processes (Varela 1999, Gallagher 2016). The narrative timescale is the time of reflective consciousness, long-term memory, expectations, discourse, and explicit goal-seeking behavior.

Elementary, integrative, and narrative timescales are dynamically nonlinear; accordingly, cognitive processes are not straightforwardly contemporaneous across levels. They are not simply diachronic if we think of diachronicity as involving mere succession, and they are not necessarily additive or sequential across different timescales. For example, auditory and visual signals are processed at different rates at the elementary timescale, and yet they are experientially bound together at the integrative timescale. Thus, Varela suggests that these timescales are recursively and hierarchically structured to compose unified wholes. The explication of these time scales "addresses the question of how something temporally extended can show up as present but also reach far into my temporal horizon" (1999: 116-17). Specifically, Varela suggests that neuronal activations at the elementary level become coupled through dynamically instable phase-locking syntheses that manifest through retentional processes as conscious, behavioral, or action moments on the integrational level. The instability of phase-locked synchrony that transitions into relaxation states and phase transition generates the flow of experience.

In brief, we have neuronal-level constitutive events, which have a duration on the $1 / 10$ scale, forming aggregates that manifest as incompressible but complete cognitive acts on the 1 scale. This completion time is dynamically dependent on a number of dispersed assemblies and not a fixed integration period; in other words it is the basis of the origin of duration without an external or internally ticking clock .... The integration-relaxation processes at the 1 scale are strict correlates of present-time consciousness.

(1999: 118-19)

Importantly, these timescales characterize processes in the brain and throughout the body (West 2012), across synchronized human bodies (Fuchs 2001), and in coupling with the environment.

While predictive processing is generally presented as an internalist model, as we see in Hohwy (2013) and Hohwy et al. (2016), it has also been proposed as a model that can integrate embodied and environmental aspects. Andy Clark, for example, suggests that predictive processing provides "the perfect neuro-computational partner for recent work on the embodied mind-work that stresses the constant engagement of 
the world by cycles of perceptual-motor activity" (2016: 1). In effect, Clark (ibid., 133), in contrast to Hohwy, emphasizes active inference-active, embodied engagement that manipulates the environment in order to reduce prediction errors. "The predictive brain, if this is correct, is not an insulated inference engine so much as an actionoriented engagement machine" (ibid., 1).

Thinking of cognitive and action-related processes in terms of predictive engagement means, on a phenomenologically informed enactive reading, thinking of these processes in terms of dynamical adjustments "in which the brain, as part of and along with the larger organism, actively responds in ways that allow for the right kind of ongoing attunement with the environment-an environment that is physical but also social and cultural" (Gallagher and Allen 2018: 2634). On this view, active inference is a dynamic engagement with the world that integrates exteroceptive, interoceptive, and proprioceptive factors (see Seth 2013, Seth and Friston 2016). It is not something that is simply computable within the brain but requires an embodied agent embedded within an environment.

The recursivity that Varela describes in terms of the nonlinear dynamics across different timescales is described by Clark as processes of "rolling cycles" that involve action and perception, so that "what we perceive is constantly conditioned by what we do," and vice versa. In an ongoing reciprocal causal fashion, top-down predictions entrain actions that "help sculpt the sensory flows that recruit new highlevel predictions (and so on, in a rolling cycle of expectation, sensory stimulation and action)" (2016: 176). In predictive engagement, where brain, body, and environment are dynamically integrated across different timescales, both affective (interoceptive) processes and agentive practical interests drive the process. According to Clark, these processes are "pragmatic" insofar as "they are adapted to produce good control" for a set of possible actions "constantly conditioned by our own 'action repertoire' ... in interaction with our needs, projects, and opportunities" (2016: 180).

Varela also links affectivity to the ongoing processes of intrinsic temporality. Specifically, protention "is always suffused with affect and emotional tone that accompanies the flow" (1999: 131). Protention is not an abstract, merely formal or dis-interested prediction. In predictive processing terms, the prior that shapes the protention is affectively suffused and practically interested. Varela cites Husserl's unpublished C-manuscript, to indicate that the agent "follows affect, or still it is attracted, held, taken in by that which affects it" (Ms. CIII/1, Varela 1999: 131). In this regard, affect has an impact on the structure of intrinsic temporality. Here he quotes Natalie Depraz's insight into Husserl's analysis: "Affect is there before being there for me in full consciousness: I am affected before knowing that I am affected. It is in that sense that affect can be said to be primordial" (Depraz 1994: 75).

This idea is clearly captured in predictive processing models. For example, Barrett and Bar (see also Barrett and Simmons 2015, Chanes and Barrett 2016) show that in regard to perception, "responses signaling an object's salience, relevance or value do not occur as a separate step after the object is identified. Instead, affective responses support vision from the very moment that visual stimulation begins" (2009: 1325). On the elemental timescale, activation of the visual cortex generates a train of muscular and hormonal changes throughout the body, generating interoceptive 
sensations from bodily organs, muscles, and joints associated with prior experience. Perception is formed in an integration (a passive synthesis) of interoception with current exteroceptive sensory information. On the integrative timescale, the organism as a whole responds and contributes to shaping subsequent actions. This ongoing integration of "sensory information from the external world with that from the body indicates that conscious percepts are indeed intrinsically infused with affective value, so that the affective salience or significance of an object is not computed after the fact." Accordingly, "the predictions generated during object perception carry affective value as a necessary and normal part of visual experience" (Barrett and Bar 2009: 1328). As Gallagher and Allen (2018) suggest, priors, which include affect, are not just in the brain but involve whole body dispositions and adjustments.

The specious present and modulations in our experience of time can be understood within a predictive processing model by taking into account the affective and embodied processes involved in the temporal flow of experience. If protention is in some sense prediction, retention the updating of posteriors, and primal impression the updating of priors (Hohwy et al. 2016: 328), these elements are interlaced by different timescales operating across the brain, body, and environment. This dynamic interrelation of timescales across brain, body, and environment composes a predictive engagement with the world. At the narrative timescale, goal-oriented behavior hierarchically modifies passive and active synthesizing processes at the integrative and elementary timescales. Affective salience drives the dynamic interaction of timescales at all levels. When affective salience is modified, we can expect that temporal phenomenology will correlatively undergo a modification. In the following section, we trace one such modification in depression.

\section{Predictive Engagement and Depression}

According to Erwin Straus (1947:255), the entire symptomatology of depression involves anomalies in temporal experience. Minkowski (1970) too suggests that the generative disorder in depression involves temporality. More generally, phenomenologically informed approaches to psychopathology have described the temporality of depression as involving modifications of embodiment (Boss 1983: 113-14) and affectivity (Fuchs 2001, 2013b, 2018, Gallagher 2012, Jaspers 1997). The phenomenology of depression is marked by feelings of time slowing down, running out, or even feelings of detachment from time (Fuchs 2013b, Ratcliffe 2012, 2015).

Reality is felt purely as a temporal immediacy; or, to put it another way, we feel as if nothing were timelessly there ... "It feels as if it is always the same moment, it is like a timeless void."

(Jaspers 1997: 84)

According to Jaspers, this may be accompanied by a sense of disappearance of the future. The experience of time becomes something ossified. This corresponds to a flattening of affect and a sense of hopelessness or "the feeling of having lost feeling" 
(ibid., 111). Hopelessness is a nonspecific feeling of the emptiness of existence and not a lack of hope for any particular future state. It is related to the closing off of the future insofar as hope is fundamentally a prospective anticipation of nascent possibilities in the world (Ratcliffe 2015: 110). Hopelessness is indicative of a general closing-off of one's possibilities for engagement with the world. In this respect, and at the extreme, the protentional moment of intrinsic time is modified and no longer opens toward future possibilities.

In the DSM-5 and ICD-10 symptomatology, classical depression or Major Depressive Disorder (MDD) incorporates affective, bodily, and cognitive (call them $\mathrm{ABC}$ ) symptoms.

A. Disturbances of affect in MDD include persistent depressed mood (sadness, emptiness, hopelessness), and diminished interest in daily activities, feelings of worthlessness or guilt, but also loss of empathic resonance with others, loneliness, self-loathing or low self-esteem, pervasive sense of dread, unaccountable fears, feeling that one's experience is absolutely private and absolutely isolating, despair, feeling of being excluded, not understood, underappreciated, self-alienation.

B. Significant bodily disturbances include weight loss or gain, insomnia or hypersomnia, psychomotor agitation, and fatigue, lack of appetite, slowness of movement.

C. Disturbances in cognition include attenuation of concentration, excessive rumination, toxic thought processes, mind fog, nihilism, persistent thoughts of death, recurrent suicidal ideation. Also, as noted above, difficulty in imagining a different future, changed time perception, time experienced as passing very slowly, closure of the future. (American Psychological Association 2013: 160-1, Gallagher and Daly 2018)

These affective, bodily, and cognitive symptoms (involving interoception, proprioception, and exteroception) operate across different timescales, from the elementary to the narrative. Although not every subject with depression manifests all of these symptoms, some number of these symptoms will form a pattern, a "complete form of existence" (Merleau-Ponty 2012: 110) or "an organized and vital unity" (Minkowski 1970: 223) that defines depression.

From the perspective of both phenomenology and predictive engagement, the flattening of affect, sense of hopelessness, and feeling of the ossification of time and the loss of the future must be understood at multiple timescales. Varela (1999), for example, suggests a correlation between the three time scales (elementary, integrative, and narrative) and different forms of affect: emotional tonality (which plays into the dynamics of flow), experiential affect, and mood, respectively. At the elementary timescale, the activation of neural assemblies, embodied affective, and sensorimotor control processes undergo modification. Short-term patterns of neural activation may eventually result in long-term plastic changes including hypo- and hyperconnectivity between different regions (Kaiser et al. 2015). Altered sensorimotor control manifests as slower gait speeds (Sanders et al. 2012), lesser degrees of arm swinging in movement, reduced head movements (Michalak et al. 2009), and slouching or poor posture 
(Canales et al. 2017) and decreased sensory attenuation (Badcock et al. 2017). Hand movements, which are rapid but normally fractal when looked at in slower timescales (minutes to hours), smooth out toward Brownian noise in depressed persons (Aybek et al. 2012). This is consistent with a broader trend in illness of the breakdown of fractal patterns into noise (West 2012).

Changes in bodily (sensorimotor) and affective processes change the way the subject perceives the world. At the integrative timescale, as the body slouches, gait speed slows, and arm and head movements are reduced, there is a correlative affective flattening of affordances as objects lose their affective salience (de Haan et al. 2013, 2015). The body's active engagement with the world itself slows down. Fewer objects and events in the world affectively draw the person to action. The depressed person becomes less active, or if they maintain their level of activity, it is with a sense of futility, emptiness, and non-fulfillment. As high-level predictions of lack of affective salience develop, they reciprocally affect neural and sensorimotor processes.

Since affect contributes to the phenomenology of intrinsic time, an affective disturbance creates a disturbance in the intentional structure of experience. As we already noted, Varela thinks of protention as "always suffused with affect and emotional tone that accompanies the flow" (1999: 131, also Gallagher and Varela 2003, Varela and Depraz 2005). On this view, protention is constitutionally involved with an affective tone or tension or, from a different perspective, a readiness for action. In the case of depression, instead of the "not yet" always being suffused with an "I can," it is rather constrained by an "I cannot" or perhaps an "I'm not interested."

Not only actions but other bodily processes at narrative timescales also undergo modification. These include mood and sleep disturbances (Lee et al. 2017, Whalen et al. 2017, Wiebe et al. 2012). ${ }^{8}$ As the world consistently begins to afford fewer opportunities for action at the integrative timescale, narratives and goals at slower/ longer timescales are affected. Metanarratives about the hopelessness of existence may develop, along with a preoccupation with thoughts of death or suicidal ideation. "All that remains of the future is the increasing proximity of one's unavoidable extinction" (Ratcliffe 2015: 189-90). This feeling of hopelessness and of the hollowing out of time reflects the diminished affective salience of objects and events in the world at the integrative scale. Nevertheless, hopelessness and emptiness, as narratives structuring behavior, themselves become predictions modifying processes at elementary and integrative timescales.

The loss of affective salience at the integrative timescale and the flattening of the field of affordances may generate a higher-order prediction of general emptiness and hopelessness at the narrative timescale. This prediction, in turn, cascades into a further closing-off of the affective salience of objects in the world and reduces active inferential engagement with the world. The persistent attenuation of affordances is mirrored in the attenuation of motricity and bodily energy. There is little for the body to do or engage with, and it mirrors this lack with its own retardation and de-energization. The symptom of indecisiveness also is directly related to the flattened field of affordances. If everything is more or less irrelevant and lacking in affective salience, objects lose their ability to sway decisions either way. Quite simply, they do not afford any actions, so there is nothing to decide or to take action upon. The perception of an ossification 
or emptying of time, or a feeling of being cut-off from the future, is a direct reflection of the loss of possibilities for action in the world (Ratcliffe 2015: 110). As I adapt to the seeming inevitabilities of hopelessness and emptiness, objects and events further lose affective salience. The more I ruminate on these beliefs and the more real they become for me, the more trapped I become in the vicious cycle of depression. As the field of affordances flattens, I gain a sense of hopelessness and may even begin to imagine death or suicide as a way out. These integrative scale priors sediment in the subject and generate narrative-scale predictions (integrative $\rightarrow$ narrative). But likewise, the field of affordances becomes further flattened as my experiences of hopelessness and beliefs about death become stronger, and I begin to predict and even actively infer a situation of hopelessness (narrative $\rightarrow$ integrative). The protentional movement of prediction retroacts on the sedimentations and retentions (posterior updating), bringing them further in line with the subject's active inferential processes.

In a word, I begin to expect that everything will be hopeless, and my expectation becomes something of a self-fulfilling prophecy with repercussions at multiple timescales across brain, body, and environment. The narrative-scale predictions of hopelessness and emptiness are not cases of passive synthesis or passive inference that the agent comes to by examination of disruptions at elemental or integrative timescales. They are cases of active synthesis, part of an active inference that the agent enacts, albeit often unwittingly and unwillingly within the frame of impoverished action. Although the DSM-5 and ICD-10 symptomatology of MDD isolates individual symptoms, they are deeply connected across timescales and regions. A vital unity (Minkowski 1970: 223) or complete form of existence (Merleau-Ponty 2012: 110) forms as emergent patterns of neural activation, plastic reshaping of neural interconnectivity, sensorimotor engagements, overt behaviors, and narratives mutually implicate one another. As rapid, low-level regularities shape slower, highlevel predictions, these predictions in turn hierarchically affect the rapid predictions involved in sensorimotor and neural processes. The feeling of the hollowing out and emptying of time and hope is only the most vivid of the multiple changes occurring at all levels of the embodied agent.

\section{Conclusion}

While we agree that a predictive processing approach can enlighten the nature of the temporal flow (Hohwy et al. 2016), we have argued that the phenomenology of temporal consciousness is ultimately affective and embodied. Active inference must be understood as embodied action, beyond mere neural inferences. Perceptual processes in the specious present likewise have affective and embodied components pivotal to their structure. To understand the predictive aspect of predictive processing in terms of protention means that it is subjected to affective salience. Significant alterations in affective salience can lead to modifications in the felt passage of time in the specious present. This leads to experiences such as time apparently speeding up while deeply engrossed in an activity or slowing down in periods of boredom (where little has affective grip). 
We can see how one such modified temporal phenomenology arises in depression by noting the typical affective, bodily, and cognitive changes undergone by depressed persons. Expanding upon phenomenological analyses of depression through the lens of predictive engagement, we proposed that simultaneous bottom-up and topdown processes, from low-level perception and action to high-level, narrative-scale engagement with the world, explain this modified phenomenology. Ultimately, depression becomes a vicious circle where narrative-scale predictions and active syntheses modify elementary and integrative processes, and vice versa.

\section{Acknowledgments}

We would like to thank Kevin J. Ryan for helpful comments. Z.A.N. would like to thank the Institute of Intelligent Systems for a travel grant to present an earlier version of this paper at the XXIV World Congress of Philosophy.

\section{Notes}

1 "I find it gratuitous to assume that a Hopi who knows only the Hopi language and the cultural ideas of his own society has the same notions, often supposed to be intuitions, of time and space that we have, and that are generally assumed to be universal" (Whorf 1956: 56).

2 "A 'passive synthesis' would be contradictory if synthesis means composition, and if passivity consists in receiving a multiplicity rather than composing it. We meant, in speaking of a passive synthesis, that the multiple is penetrated by us, and that, nevertheless, we are not the ones who perform the synthesis" (Merleau-Ponty 2012: 451).

3 Error minimization is simultaneously a minimization of free energy (Friston and Kiebel 2009). Predictive processing is a hierarchical framework, with "each level providing constraints on the level below" (Friston 2005: 822). The hierarchical structure of predictive layers emulates the hierarchical causal structure of the world (Hohwy 2013, Rao 2007). Higher cortical levels predict input at lower levels. This allows for multisensory and cross-modal priors to integrate in order to produce the best possible predictions.

4 "Using the term 'inference' to describe such a process may seem to be somewhat metaphorical and thus to undercut the force of the claim that perception works by unconscious inference. But, as we said at the outset, unconscious inference must be at least somewhat metaphorical, since normal inference is quite clearly slow, laborious, and conscious, whereas perception is fast, easy, and unconscious. The important point for present purposes is that perception relies on processes that can be usefully viewed as inferences that require heuristic assumptions" (Palmer 1999: 83).

5 Grush's original model is based on the Kalman filter, not on predictive error minimization.

6 This accords with Husserl's later understanding of the primal impression in the Bernau Manuscripts, where primal impression no longer has an original content in itself but is instead woven from protentions and retentions. 
7 Cognitive processes are the result of dynamical, nonlinear integration across these time scales. Accordingly some processes are not neatly confined to one time scale, for example, working memory, which for some types of information can last up to 30 seconds (Baddeley 2007). Another example is referred to as "preparatory set," which includes proactive control processes, such as anticipations, which prepare for imminent events (Ruge et al. 2013). It is "a rapid, largely subcortical response; although it is not fully unconscious it is distinct from the conscious rational appraisal and voluntary decision-making processes" (Payne and Crane-Godreau 2015: 2).

8 These are sometime accompanied by changes in temperature, melatonin levels, and cortisol circadian rhythms (Ehlers et al. 1988, Grandin et al. 2006), as well as plastic alterations in the connectivity between neuronal regions (Kaiser et al. 2015).

\section{References}

American Psychiatric Association (2013), Diagnostic and Statistical Manual of Mental Disorders, 5th ed., Arlington, VA: American Psychiatric Association.

Aybek, S., Ionescu, A., Berney, A., Chocron, O., Aminian, K. and Vingerhoets, F. G. (2012), "Fractal Temporal Organisation of Motricity Is Altered in Major Depression," Psychiatry Research, 200: 288-93. doi.org/10.1016/j.psychres.2012.03.047.

Badcock, P. B., Davey, Christopher G., Whittle, Sarah, Allen, Nicholas B. and Friston, Karl J. (2017), “The Depressed Brain: An Evolutionary Systems Theory," Trends in Cognitive Sciences, 21 (3): 182-94. doi.org/10.1016/j.tics.2017.01.005.

Barrett, L. F. and Bar, M. (2009), "See It with Feeling: Affective Predictions during Object Perception," Philosophical Transactions of the Royal Society B: Biological Sciences, 364: 1325-34. doi.org/10.1098/rstb.2008.0312.

Barrett, L. F. and Simmons, W. K. (2015), "Interoceptive Predictions in the Brain," Nature Reviews Neuroscience, 16 (7): 419-29. doi.org/10.1038/nrn3950.

Baddeley, A. (2007), Working Memory, Thought, and Action, Oxford: Oxford University Press.

Boss, M. (1983), Existential Foundations of Medicine and Psychology, Translated by Stephen Conway and Anne Cleaves, New York: Jason Aronson.

Canales, J. Z., Fiquer, J. T., Campos, R. N., Soeiro-de-Souza, M. G. T and Moreno, R. A. (2017), "Investigation of Associations between Recurrence of Major Depressive Disorder and Spinal Posture Alignment: A Quantitative Cross-Sectional Study," Gait \& Posture, 52: 258-64. doi.org/10.1016/j.gaitpost.2016.12.011.

Chanes, L. and Barrett, L. F. (2016), "Redefining the Role of Limbic Areas in Cortical Processing," Trends in Cognitive Science, 20 (2): 96-106. doi.org/10.1016/j. tics.2015.11.005.

Clark, A. (2013), "Whatever Next? Predictive Brains, Situated Agents, and the Future of Cognitive Science," Behavioral and Brain Sciences, 36: 181-204. doi.org/10.1017/ S0140525X12000477.

Clark, A. (2016), Surfing Uncertainty: Prediction, Action, and the Embodied Mind, Oxford: Oxford University Press.

Clark, V. P., Fan, S. and Hillyard, S. A. (1995), "Identification of Early Visual Cortex by Crossmodal Spatial Attention," Human Brain Mapping, 2: 170-87.

De Haan, S., Rietveld, E., Stokhof, M. and Denys, D. (2013), “The Phenomenology of Deep Brain Stimulation-Induced Changes in OCD: An Enactive Affordance-Based Model," Frontiers in Human Neuroscience, 7: 653. doi.org/10.3389/fnhum.2013.00653. 
De Haan, S., Rietveld, E., Stokhof, M. and Denys, D. (2015), "Effects of Deep Brain Stimulation on the Lived Experience of Obsessive-Compulsive Disorder Patients: InDepth Interviews with 18 Patients," PLoS One, 10 (8): 1-29. doi.org/10.1371/journal. pone.0135524.

Depraz, N. (1994), "Temporalité et affection dans les manuscrits tardifs sur la temporalité (1929-1935) de Husserl," Alter, 2: 63-86.

Doya, K., Ishii, S., Pouget, A. and Rao, R. P. N. (eds.) (2007), Bayesian Brain: Probabilistic Approaches to Neural Coding, Cambridge: MIT Press.

Edwards, A. M. and McCormick, A. (2017), “Time Perception, Pacing and Exercise Intensity: Maximal Exercise Distorts the Perception of Time," Physiology \& Behavior, 180: 98-102. doi.org/10.1016/j.physbeh.2017.08.009.

Ehlers, C. L., Frank, E. and Kupfer, D. J. (1988), "Social Zeitgebers and Biological Rhythms: A Unified Approach to Understanding the Etiology of Depression," Archives of General Psychiatry, 45 (10): 948-52. doi.org/10.1001/archps yc.1988.01800340076012.

Favela, L. H. and Chemero, A. (2016), “The Animal-Environment System” in Yann Coello and Martin H. Fischer (eds.), Foundations of Embodied Cognition: Perceptual and Emotional Embodiment, New York: Routledge, pp. 59-74.

Foxe, J. J. and Simpson, G. V. (2002), "Flow of Activation from V1 to Frontal Cortex in Humans," Experimental Brain Research, 142 (1): 139-50. doi.org/10.1007/s00221-0010906-7.

Friedman, W. J. (1990), About Time: Inventing the Fourth Dimension, Cambridge: MIT Press.

Friston, K. (2005), "A Theory of Cortical Responses," Philosophical Transactions of the Royal Society B, 360: 815-36. doi.org/10.1098/rstb.2005.1622.

Friston, K. and Kiebel, S. (2009), "Predictive Coding under the Free-Energy Principle," Philosophical Transactions of the Royal Society B: Biological Sciences, 364: 1211-21. doi. org/10.1098/rstb.2008.0300.

Fuchs, T. (2001), "Melancholia as a Desynchronization: Towards a Psychopathology of Interpersonal Time," Psychopathology, 34: 179-86. doi.org/10.1159/000049304.

Fuchs, T. (2013a), "Depression, Intercorporeality, and Interaffectivity," Journal of Consciousness Studies, 20 (7-8): 219-38.

Fuchs, T. (2013b), “Temporality and Psychopathology," Phenomenology and Cognitive Science, 12: 75-104. doi.org/10.1007/s11097-010-9189-4.

Fuchs, T. (2018), Ecology of the Brain: The Phenomenology and Biology of the Embodied Mind, Oxford: Oxford University Press.

Fung, B. J., Murawski, C. and Bode, S. (2017), "Caloric Primary Rewards Systematically Alter Time Perception," Journal of Experimental Psychology: Human Perception and Performance, 43 (11): 1925-36. doi.org/10.1037/xhp0000418.

Gable, P. A., Neal, L. B. and Poole, B. D. (2016), "Sadness Speeds and Disgust Drags: Influence of Motivational Direction on Time Perception in Negative Affect," Motivation Science, 2 (4): 238-55. doi.org/10.1037/mot0000044.

Gallagher, S. (2011), "Time in Action" in C. Callender (ed.), Oxford Handbook on Time, Oxford: Oxford University Press, pp. 419-37.

Gallagher, S. (2012), “Time, Emotion, and Depression,” Emotion Review, 4 (2): 127-32. doi.org/10.1177/1754073911430142.

Gallagher, S. (2016), “Timing Is Not Everything: The Intrinsic Temporality of Action” in Roman Altshuler and Michael J. Sigrist (eds.), Time and the Philosophy of Action, New York: Routledge. 
Gallagher, S. (2017a), Enactivist Interventions: Rethinking the Mind, Oxford: Oxford University Press.

Gallagher, S. (2017b), “The Past, Present and Future of Time-Consciousness: From Husserl to Varela and Beyond," Constructivist Foundations, 13 (1): 91-7.

Gallagher, S. (2018), "New Mechanisms and the Enactivist Concept of Constitution" in M. P. Guta (ed.), Consciousness and the Ontology of Properties, London: Routledge, pp. 207-20. doi.org/10.4324/9781315104706.

Gallagher, S. and Allen, M. (2018), "Active Inference, Enactivism and the Hermeneutics of Social Cognition," Synthese, 195 (6): 2627-48. doi.org/10.1007/s11229-016-1269-8.

Gallagher, S. and Daly, A. (2018), "Dynamical Relations in the Self-Pattern," Frontiers in Psychology, 9: 664. doi.org/10.3389/fpsyg.2018.00664.

Gallagher, S. and Varela, F. J. (2003), "Redrawing the Map and Resetting the Time: Phenomenology and the Cognitive Sciences," Canadian Journal of Philosophy, 29: 93-132. doi.org/10.1080/00455091.2003.10717596.

Gallagher, S. and Zahavi, D. (2014), "Primal Impression and Enactive Perception" in Valtteri Arstila and Dan Lloyd (eds.), Subjective Time: The Philosophy, Psychology, and Neuroscience of Temporality, Cambridge: MIT Press.

Grandin, L. D., Alloy, L. B. and Abramson, L. Y. (2006), "The Social Zeitgeber Theory, Circadian Rhythms, and Mood Disorders: Review and Evaluation," Clinical Psychological Review, 26: 679-94. doi.org/10.1016/j.cpr.2006.07.001.

Grush, R. (2007), "Skill Theory 2.0: Dispositions, Emulation, and Spatial Perception," Synthese, 159: 389-416. doi.org/10.1007/s11229-007-9236-z.

Grush, R. (2008), “Temporal Representation and Dynamics," New Ideas in Psychology, 26: 146-57. doi.org/10.1016/j.newideapsych.2007.07.017.

Hatfield, G. (2002), "Perception as Unconscious Inference" in D. Heyer (ed.), Perception and the Physical World: Psychological and Philosophical Issues in Perception, Chichester: John Wiley \& Sons, pp. 113-43.

Heidegger, M. (1972), On Time and Being, Translated by Joan Stambaugh, New York: Harper \& Row.

Heidegger, M. (2010), Being and Time, rev. ed., Translated by Joan Stambaugh, Albany: State University of New York Press.

Heidegger, M. (2012), Contributions to Philosophy (of the Event), Translated by Richard Rojcewicz and Daniela Vallega-Neu, Bloomington: Indiana University Press.

Helmholtz, H. V. (1962), Treatise on Physiological Optics, Volume III, 3rd ed., Translated by James P. C. Southall, New York: Dover.

Hohwy, J. (2013), The Predictive Mind, Oxford: Oxford University Press.

Hohwy, J. (2016), "The Self-Evidencing Brain," Noûs, 50 (2): 259-85. doi.org/10.1111/ nous. 12062 .

Hohwy, J., Patton, B. and Palmer, C. (2016), “Distrusting the Present," Phenomenology and the Cognitive Sciences, 15: 315-35. doi.org/10.1007/s11097-015-9439-6.

Hollingworth, H. L. (1910), “The Central Tendency of Judgment,” The Journal of Philosophy, Psychology and Scientific Methods, 7 (17): 461-9. doi.org/10.2307/2012819.

Husserl, E. (1991), On the Phenomenology of the Consciousness of Internal Time, Translated by John B. Brough, Dordrecht: Kluwer Academic.

Husserl, E. (2001), Analyses Concerning Passive and Active Synthesis: Lectures on Transcendental Logic, Translated by Anthony J. Steinbock, Dordrecht: Kluwer Academic.

Hutto, D. (2018), “Getting into Predictive Processing's Great Guessing Game: Bootstrap Heaven or Hell?” Synthese, 195: 2445-58. doi.org/10.1007/s11229-017-1385-0. 
James, W. (1890), The Principles of Psychology, New York: Henry Holt and Co.

Jaspers, K. (1997), General Psychopathology, Volume 1, Translated by J. Hoenig and Marian W. Hamilton, Baltimore, MD: Johns Hopkins University Press.

Kaiser, R. H., Andrews-Hanna, J., Wagner, T. and Pizzagalli, D. A. (2015), "Large-Scale Network Dysfunction in Major Depressive Disorder: A Meta-analysis of RestingState Functional Connectivity," JAMA Psychiatry, 72 (6): 603-11. doi.org/10.1001/ jamapsychiatry.2015.0071.

Lee, J. E., Park, S., Nam, J.-Y., Young, J. J., and Park, E.-C. (2017), "Effect of Changes in Sleep Quantity and Quality on Depressive Symptoms among Korean Children," The Journal of School Nursing, 33 (4): 299-306. doi.org/10.1177/1059840516660015.

Marr, D. (2010), Vision: A Computational Investigation into the Human Representation and Processing of Visual Information, Cambridge: MIT Press.

Merleau-Ponty, M. (1968), The Visible and the Invisible, Translated by Alphonso Lingis, Evanston, IL: Northwestern University Press.

Merleau-Ponty, M. (2012), Phenomenology of Perception, Translated by Donald A. Landes, New York: Routledge.

Michalak, J., Troje, N. F., Fischer, J., Vollmar, P., Heidenreich, T. and Schulte, D. (2009), "Embodiment of Sadness and Depression-Gait Patterns Associated with Dysphoric Mood," Psychosomatic Medicine, 71: 580-7. doi.org/10.1097/PSY.0b013e3181a2515c.

Minkowski, E. (1970), Lived Time: Phenomenological and Psychopathological Studies, Translated by Nancy Metzel, Evanston, IL: Northwestern University Press.

Moore, J. W. and Obhi, S. S. (2012), "Intentional Binding and the Sense of Agency: A Review," Consciousness and Cognition, 21 (1): 546-61. doi.org/10.1016/j. concog.2011.12.002.

Palmer, S. E. (1999), Vision Science: Photons to Phenomenology, Cambridge, MA: MIT Press.

Payne, P. and Crane-Godreau, M. A. (2015), “The Preparatory Set: A Novel Approach to Understanding Stress, Trauma, and the Bodymind Therapies," Frontiers in Human Neuroscience, 9: 1-22. doi.org/10.3389/fnhum.2015.00178.

Rao, R. P. N. (2007), “Neural Models of Bayesian Belief Propagation” in Kenji Doya, Shin Ishii, Alexandre Pouget, and Rajesh P. N. Rao (eds.), Bayesian Brain: Probabilistic Approaches to Neural Coding, Cambridge: MIT Press.

Ratcliffe, M. (2012), "Variety of Temporal Experience in Depression," Journal of Medical Philosophy, 37 (2): 114-38. doi.org/10.1093/jmp/jhs010.

Ratcliffe, M. (2015), Experiences of Depression: A Study in Phenomenology, Oxford: Oxford University Press.

Ruge, H., Jamadar, S., Zimmermann, U. and Karayanidis, F. (2013), “The Many Faces of Preparatory Control in Task Switching: Reviewing a Decade of fMRI Research," Human Brain Mapping, 34: 12-35. doi.org/10.1002/hbm.21420.

Sanders, J. B., Bremmer, M. A., Deeg, D., Beekman J. H. and Aartjan, T. F. (2012), “Do Depressive Symptoms and Gait Speed Impairment Predict Each Other's Incidence? A 16-Year Prospective Study in the Community," Journal of the American Geriatrics Society, 60 (9): 1673-80. doi.org/10.1111/j.1532-5415.2012.04114.x.

Seth, A. K. (2013), "Interoceptive Inference, Emotion, and the Embodied Self," Trends in Cognitive Sciences, 17 (11): 565-73. doi.org/10.1016/j.tics.2013.09.007.

Seth, A. K. and Friston, K. J. (2016), "Active Interoceptive Inference and the Emotional Brain," Philosophical Transactions of the Royal Society B, 371 (1708): 1-10. doi. org/10.1098/rstb.2016.0007. 
Shi, Z. and Burr, D. (2016), "Predictive Coding of Multisensory Timing," Current Opinion in Behavioral Sciences, 8: 200-6. doi.org/10.1016/j.cobeha.2016.02.014.

Spratling, M. W. (2013), "Distinguishing Theory from Implementation in Predictive Coding Accounts of Brain Function," Behavioral and Brain Sciences, 36 (3): 231-2. doi. org/10.1017/S0140525X12002178.

Straus, E. (1947), "Disorders of Personal Time in Depressive States," Southern Medical Journal, 40 (3): 254-9.

Telban, B. (2017), "Seeing and Holding Time: Karawari Perceptions of Temporalities, Calendars and Clocks," Time \& Society, 26 (2): 182-202. doi.org/10.1177/096146 3X15577273.

Thönes, S. and Wittmann, M. (2016), “Time Perception in Yogic Mindfulness Meditation-Effects on Retrospective Duration Judgments and Time Passage," Psychology of Consciousness: Theory, Research, and Practice, 3 (4): 316-25. doi. org/10.1037/cns0000088.

Uusberg, A., Naar, R., Tamm, M., Kreegipuu, K. and Gross, J. J. (2018), “Bending Time: The Role of Affective Appraisal in Time Perception," Emotion 18 (8): 1174-88. doi. org/10.1037/emo0000397.

Van Hedger, K., Necka, E. A., Barakzai, A. K. and Norman, G. J. (2017), “The Influence of Social Stress on Time Perception and Psychophysiological Reactivity," Psychophysiology, 54: 706-12. doi.org/10.1111/psyp.12836.

Varela, F. J. (1999), "The Specious Present: A Neurophenomenology of Time Consciousness" in Jean Petitot, Francisco J. Varela, Bernard Pachoud, and Jean-Michel Roy (eds.), Naturalizing Phenomenology: Issues in Contemporary Phenomenology and Cognitive Science, Stanford: Stanford University Press.

Varela, F. J. and Depraz, N. (2005), "At the Source of Time: Valence and the Constitutional Dynamics of Affect," Journal of Consciousness Studies, 12 (8-10): 61-81.

Vaughan, H. G. and Arezzo, J. C. (1988), “The Neural Basis of Event-Related Potentials" in T. W. Picton (ed.), Human Event-Related Potentials. Handbook of Electroencephalography and Clinical Neurophysiology. Revised Series, Vol. 3, Amsterdam: Elsevier, pp. 45-96.

Vaughan, H. G., Ritter, W. and Simson, R. (1980), “Topographic Analysis of Auditory Event-Related Potentials.” Progress in Brain Research, 54: 279-85. doi.org/10.1016/ S0079-6123(08)61635-0.

Wearden, J. (2016), The Psychology of Time Perception, London: Palgrave Macmillan.

Wearden, J. H., Todd, N. P. M. and Jones, L. A. (2006), "When Do Auditory/Visual Differences in Duration Judgments Occur?" The Quarterly Journal of Experimental Psychology, 59 (10): 1709-24. doi.org/10.1080/17470210500314729.

West, B. J. (2012), Fractal Physiology and Chaos in Medicine, 2nd ed., Singapore: World Scientific.

Whalen, D. J., Gilbert, Kirsten E., Barch, Deanna M., Luby, Joan L. and Belden, Andy C. (2017), "Variation in Common Preschool Sleep Problems as an Early Predictor for Depression and Anxiety Symptom Severity across Time," The Journal of Child Psychology and Psychiatry, 58 (2): 151-9. doi.org/10.1111/jcpp.12639.

Whorf, B. L. (1956), Language, Thought, and Reality: Selected Writings of Benjamin Lee Whorf, edited by John B. Carroll, Cambridge: MIT Press.

Wiebe, S. T., Cassoff, J. and Gruber, R. (2012), "Sleep Patterns and the Risk for Unipolar Depression: A Review," Nature and the Science of Sleep, 4: 63-71. doi.org/10.2147/NSS. S23490. 